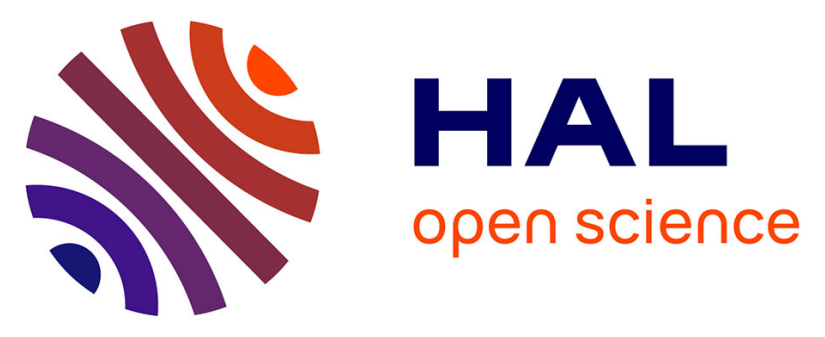

\title{
Septohippocampal pathways contribute to system consolidation of a spatial memory: Sequential implication of gabaergic and cholinergic neurons
}

Lucas Lecourtier, Anne Pereira de Vasconcelos, Elise Leroux, Brigitte

Cosquer, Karin Geiger, Ségolène Lithfous, Jean-Christophe Cassel

\section{To cite this version:}

Lucas Lecourtier, Anne Pereira de Vasconcelos, Elise Leroux, Brigitte Cosquer, Karin Geiger, et al. Septohippocampal pathways contribute to system consolidation of a spatial memory: Sequential implication of gabaergic and cholinergic neurons. Hippocampus, 2011, 21 (12), pp.1277-1289. 10.1002/hipo.20837 . hal-03037845

\section{HAL Id: hal-03037845 https://hal.science/hal-03037845}

Submitted on 3 Nov 2021

HAL is a multi-disciplinary open access archive for the deposit and dissemination of scientific research documents, whether they are published or not. The documents may come from teaching and research institutions in France or abroad, or from public or private research centers.
L'archive ouverte pluridisciplinaire HAL, est destinée au dépôt et à la diffusion de documents scientifiques de niveau recherche, publiés ou non, émanant des établissements d'enseignement et de recherche français ou étrangers, des laboratoires publics ou privés. 


\section{Septohippocampal pathways contribute to system consolidation of a spatial memory: Sequential implication of gabaergic and cholinergic neurons}

Lucas Lecourtier, Anne Pereira de Vasconcelos, Elise Leroux, Brigitte

Cosquer, Karin Geiger, Ségolène Lithfous, Jean-Christophe Cassel

\section{To cite this version:}

Lucas Lecourtier, Anne Pereira de Vasconcelos, Elise Leroux, Brigitte Cosquer, Karin Geiger, et al.. Septohippocampal pathways contribute to system consolidation of a spatial memory: Sequential implication of gabaergic and cholinergic neurons. Hippocampus, Wiley, 2011, 21 (12), pp.1277-1289. 10.1002/hipo.20837 . hal-03037845

\section{HAL Id: hal-03037845 \\ https://hal.archives-ouvertes.fr/hal-03037845}

Submitted on 3 Nov 2021

HAL is a multi-disciplinary open access archive for the deposit and dissemination of scientific research documents, whether they are published or not. The documents may come from teaching and research institutions in France or abroad, or from public or private research centers.
L'archive ouverte pluridisciplinaire HAL, est destinée au dépôt et à la diffusion de documents scientifiques de niveau recherche, publiés ou non, émanant des établissements d'enseignement et de recherche français ou étrangers, des laboratoires publics ou privés. 


\title{
Septohippocampal Pathways Contribute to System Consolidation of a Spatial Memory: Sequential Implication of GABAergic and Cholinergic Neurons
}

\author{
Lucas Lecourtier, Anne Pereira de Vasconcelos, Elise Leroux, Brigitte Cosquer, \\ Karin Geiger, Ségolène Lithfous, and Jean-Christophe Cassel*
}

\begin{abstract}
Studies of the neuropharmacological substrates of spatial memory formation have focused on the contribution of septohippocampal pathways. Although these pathways include, among others, cholinergic and GABAergic fibers innervating the hippocampus, research has essentially been oriented towards the role of their cholinergic component. Recently, a few studies investigated the role of GABAergic septohippocampal projections. These only focused on almost immediate or recent memory and yielded discrepant results. GABAergic lesions impaired learning or had no effects. Given the role of the hippocampus in memory consolidation and the potential modulatory influence of the septum on hippocampal function, it is relevant to study the role of the septohippocampal interface in memory stabilization. We performed investigations with relatively selective lesions of GABAergic (using oxerin-saporin) or/and cholinergic (using 192 IgG-saporin) medial septum/vertical limb of the diagonal band of Broca (MS/vDBB) neurons in rats, and assessed acquisition of a spatial memory and its subsequent recall in the water maze. Following a 6-day training phase during which all groups improved performance to comparable levels, retention was tested 1, 5, or 25 days later. At the 1-day delay, all groups performed above chance and did not differ significantly among each other. At the 5-day delay, only rats with GABAergic or combined lesions exhibited a retention deficit. At the 25-day delay, all three lesion groups performed at chance level; in these groups, performance was significantly lower than that found in sham-operated rats. Immunochemical and histochemical verifications of the lesion extent/selectivity showed extensive GABAergic damage after intraseptal orexin-saporin infusions or cholinergic damage after 192 IgG-saporin infusions, with relatively limited damage to the other neurotransmitter system. Our data show that GABAergic and cholinergic septohippocampal neurons both contribute to memory stabilization, and could do so in a sequential way: GABAergic processes could be engaged at an earlier stage than cholinergic ones during system consolidation of a spatial memory.
\end{abstract}

KEY WORDS: medial septum; neurotoxic lesions; water maze; recent and remote memory; Long-Evans rat

Laboratoire d'Imagerie et de Neurosciences Cognitives, FRE 3289, Université de Strasbourg - CNRS, Faculté de Psychologie, 67000 Strasbourg, France

Additional Supporting Information may be found in the online version of this article.

*Correspondence to: Dr. Jean-Christophe Cassel, Laboratoire d'Imagerie et de Neurosciences Cognitives, 12 rue Goethe, 67000 Strasbourg, France. E-mail: jcassel@unistra.fr

Accepted for publication 14 May 2010

DOI 10.1002/hipo.20837

Published online in Wiley InterScience (www.interscience.wiley.com).

\section{INTRODUCTION}

The medial septum and vertical limb of the diagonal band of Broca (MS/vDBB) constitute major sources of hippocampal innervation (Paxinos and Watson, 1995). They encompass cholinergic and GABAergic neurons, which immunostain for cholineacetyltransferase (ChAT) and Parvalbumin (Parv), respectively (Freund and Antal, 1988; Paxinos and Watson, 1995), and both project to the hippocampus. To unravel the neuroanatomical and neuropharmacological substrates of hippocampus-dependent memory processes, and primarily of those involved in spatial memory, research has often focused on the septohippocampal connections. In rodents, inactivation or complete lesions of the MS/vDBB induce severe memory deficits in a variety of tasks including the very popular Morris water-maze task, which taxes declarative-like memory in rodents (Kelsey and Landry, 1988; Rashidy-Pour et al., 1996; Koenig et al., 2008). Because memory dysfunctions are a relatively systematic correlate of anticholinergic treatments and damage encroaching onto cholinergic MS/vDBB neurons, the aforementioned deficits were often attributed to the disruption of cholinergic neurons within the septohippocampal interface. However, following selective damage to these neurons, rats are still able to acquire a platform location in a water-maze task (Berger-Sweeney et al., 1994; Baxter et al., 1995; Dornan et al., 1996). More recently, an implication of septohippocampal GABAergic neurons in spatial memory has been postulated. These neurons modulate hippocampal theta activity (Yoder and Pang, 2005; Hangya et al., 2009) and neurogenesis (Van der Borght et al., 2005), two phenomena often related to memory acquisition and consolidation. We recently reported that the activation of 5-hydroxytryptamine $_{1 \mathrm{~A}}$ receptors in the $\mathrm{MS} / \mathrm{vDBB}$ impaired performance in the water maze (Koenig et al., 2008). As these receptors are expressed on $98 \%$ of septum (MS)/vDBB Parv-positive GABAergic neurons (Lüttgen et al., 2005), our data further support the idea of a contribution of GABAergic neurons to spatial memory. However, the rare investigations performed so far with relatively selective lesions of septal GABAergic neurons yielded 
discrepant results: memory can be impaired (Dwyer et al., 2007) or not (Pang et al., 2001). In addition, these investigations only focused on recent memory. The issue of the postacquisition duration of a spatial memory following GABAergic lesions in the septohippocampal pathway has, to our knowledge, never been addressed; interestingly, the same remark applies to the cholinergic component of these pathways. This issue appears relevant as hippocampal circuits do not seem to contribute identically to processes involved in storage/retrieval of some forms of remote memory (Nadel and Moscovitch, 1997; Frankland and Bontempi, 2005). Finally, the neuropharmacological dynamics of remote vs. recent memory formation remain a terra incognita. Therefore, using neurotoxins, we induced lesions encroaching mainly onto GABAergic or/and cholinergic septal neurons in rats subsequently trained in a water maze; retention was tested in a probe trial 1,5 or 25 days after task acquisition. Single or combined, the lesions did not alter final levels of task acquisition. They both hindered memory retrieval but much earlier after GABAergic (from 5 days onward) than after cholinergic lesions (25 days).

\section{MATERIALS AND METHODS}

\section{Subjects}

Adult male Long-Evans rats (200-220 g on arrival; Centre d'Elevage R. Janvier, Le Genest St-Isle, France) were housed in individual cages (Makrolon, $42 \times 26 \times 15 \mathrm{~cm}^{3}$ ) and maintained on a 12-h light/12-h dark cycle (lights on at 7:00 h) in temperature-controlled $\left(23 \pm 1{ }^{\circ} \mathrm{C}\right)$ rooms. After their arrival, the rats were acclimatized to the laboratory over 1 week. They had ad libitum access to food and water throughout the study. Surgery and behavioral testing were performed during the light period. During 2 days before the start of the test, rats were familiarized with the experimental room in which the watermaze test was installed. All procedures were conducted in conformity with the institutional guidelines that are in compliance with the national council directive no. 87848, October 19, 1987, Ministère de l'Agriculture et de la Forêt: (C-67-482-13), the French law on researcher agreement (67-215 to J.C.C.; 677 to A.P.V.; 67-358 to K.G.; other authors under the former's responsibility), and international laws and policies (National Institutes of Health publication no. 85-23, revised 1985).

\section{Immunotoxin Solutions}

To achieve acceptable selectivity in the depletion of cholinergic SM/vDBB neurons, the neurotoxin 192 IgG-saporin was used as previously described (Lehmann et al., 2003; van der Staay et al., 2006; Traissard et al., 2007). For a relatively selective damage of GABAergic SM/vDBB neurons, the neurotoxin orexin-saporin was used as previously described by Smith and Pang (2005). Aliquots of $1 \mu \mathrm{g} / \mu \mathrm{l}$ stock solutions of $192 \mathrm{IgG}$ saporin and orexin-saporin (ATS, San Diego, CA; batches 41-
105 and 21-163, respectively) were prepared by addition of filtered phosphate buffered saline (PBS) to the stock solution. The aliquots were kept frozen at $-80^{\circ} \mathrm{C}$. On each day of surgery, fresh dilutions were performed (in PBS) to obtain $0.14 \mu \mathrm{g} / \mu \mathrm{l}$ orexin-saporin and $0.8 \mu \mathrm{g} / \mu \mathrm{l} 192 \mathrm{IgG}$-saporin solutions. During surgery, the toxins were kept on ice. Investigations on combined lesions were performed by the administration of a mixed solution containing $0.14 \mu \mathrm{g} / \mu \mathrm{l}$ orexin-saporin and $0.8 \mu \mathrm{g} / \mu \mathrm{l} 192 \mathrm{IgG}$-saporin.

\section{Surgical Procedures}

Rats were administered scopolamine methyl bromide $(0.02$ $\mathrm{mg} / \mathrm{kg}$, ip) $15 \mathrm{~min}$ prior to anesthesia (sodium pentobarbital, $60 \mathrm{mg} / \mathrm{kg}$, ip), to reduce bronchial secretions and minimize usual respiratory difficulties accompanying pentobarbital anesthesia. The rats were placed in a stereotaxic frame with the tooth bar set $-3.3 \mathrm{~mm}$ above the level of the ear bars (Paxinos and Watson, 1998). The scalp was shaved, then incised, and holes were drilled bilaterally into the skull above the MS/vDBB region. Solutions were infused by means of a $1 \mu$ l Hamilton syringe fixed along the vertical arm of the stereotaxic frame. On each side consecutively, a first $0.25 \mu \mathrm{l}$ infusion was performed in the vDBB $(0.6 \mathrm{~mm}$ anterior and $\pm 0.2 \mathrm{~mm}$ lateral to bregma, $7.5 \mathrm{~mm}$ ventral to the skull surface) and the needle was left in place for $2 \mathrm{~min}$ after the end of the infusion. Then, the needle was gently lifted to reach the MS $(0.6 \mathrm{~mm}$ anterior and $\pm 0.2 \mathrm{~mm}$ lateral to bregma, $6.5 \mathrm{~mm}$ ventral to the skull surface), another $0.25 \mu \mathrm{l}$ infusion was performed and the needle was left in place for $5 \mathrm{~min}$ after this second infusion. After these $5 \mathrm{~min}$, it was gently lifted $1 \mathrm{~mm}$ and left in place for additional $3 \mathrm{~min}$. Finally, it was slowly retracted from the brain. This stepwise timing prevented reflux of the infused toxins. Overall, the rats received either $400 \mathrm{ng}$ of $192-\mathrm{IgG}$ saporin per side (SAP group), or $70 \mathrm{ng}$ of orexin-saporin per side (OREX group), or $400 \mathrm{ng}$ of $192 \mathrm{IgG}$-saporin $+70 \mathrm{ng}$ of orexin-saporin per side and in the same volume as for the single toxin injections (SAP/OREX group). These quantities were selected on the basis of preliminary experiments testing extent and selectivity of the lesions for each toxin. The sham-operated rats were subjected to the same infusion protocol except that they were administered only filtered PBS in equal volumes. After completion of the infusion protocol, the skin was sutured, the rats were subjected to an intramuscular injection of the antibiotic extencillin (Sanofi-Aventis, 2.4 international milli units (MUI) in $8 \mathrm{ml}$ solvent solution, $1 \mathrm{ml} / \mathrm{kg}$ ) and they were placed under a warm lamp until they woke up. After surgery, they were allowed 10 days of rest before testing was started.

\section{Apparatus: The Morris Water Maze}

The Morris water maze consisted of a circular white-plastic pool, $160.5 \mathrm{~cm}$ in diameter and $60 \mathrm{~cm}$ in depth. It was filled with water at room temperature $\left(23 \pm 1^{\circ} \mathrm{C}\right)$ to half its height. The water was made opaque by addition of powdered milk (about $500 \mathrm{~g} / 200 \mathrm{l}$ ). The pool was located in an experimental room with visual extra-maze cues positioned on each of the 
room walls. The cues were numerous and very salient to prevent degradation of remote memory performance in naïve nonoperated rats (Lopez et al, 2008a). The movements of the rats were followed by a computer-based video tracking system (Ethovision, Noldus, The Netherlands).

\section{Spatial Reference Memory Task}

In this study, the water-maze training was started after we had performed the lesions, whereby damage was present during the whole course of acquisition and might have influenced acquisition (encoding or/and consolidation). Despite this drawback, the option of postsurgical training was chosen because (i) preliminary experiments (unpublished data) in a limited number of rats have shown that, regardless of the lesion type, performance levels were comparable after 5 days of water-maze training and were not different from controls (training was nevertheless increased to 6 days in this study; see the following sections), (ii) at least 192 IgG-saporin-induced cholinergic lesions establish progressively and require 7 to 10 days before being complete (e.g., Book et al., 1992; Waite et al., 1994). Strictly speaking, this interval before lesion completeness is compatible with an experimental design based on postacquisition surgery, but not at all with the aim to test memory retrieval at postacquisition delays as short as 1 or 5 days. Regarding this technical constraint, the earliest acceptable delay would be about 10 days, a delay at which a memory trace can already be regarded as remote (Frankland and Bontempi, 2005). Thus, postacquisition surgery with immunotoxins is compatible with testing remote memory, not with testing recent memory.

\section{Training}

The training was performed over 6 consecutive days to enable the establishment of a relatively robust memory, which can still be recalled after 25 days of postacquisition rest in rats with an intact brain (Lopez et al., 2008a). Training and the subsequent probe trial were performed in a cue-enriched room described in detail elsewhere (Lopez et al., 2008a,b). During training, the hidden escape platform remained in the Northwest quadrant. On each test day, the animals received a block of four consecutive trials: they were placed once at each of four starting positions in a different pseudorandomized order each day, facing the wall of the pool, and were allowed a $60 \mathrm{~s}$ time to find the platform and climb onto it. When they found the platform, they were left there for $10 \mathrm{~s}$ before the start of the next trial. A rat that did not find the platform within the $60 \mathrm{~s}$ was gently guided to it by the experimenter and left there for $10 \mathrm{~s}$ before the next trial was started. The distance covered (and latency) to climb onto the platform was recorded for each trial. Additional analyses focused on the time taken to find the platform and the time spent along the edge of the pool (thigmotaxic behavior).

\section{Retention Testing}

For the retention test (probe trial), the platform was removed, the rats were released all from the same starting point for a single trial and allowed to swim for $60 \mathrm{~s}$. The time spent in each of the four quadrants was recorded and used for further analysis of memory retention performance. The percentage of time spent in each quadrant was calculated and performance was considered to be at chance level (i.e., no retention of platform location) when the time spent in the target quadrant was not significantly different from $25 \%$ of trial duration.

\section{Histological Verifications}

To assess the selectivity of both toxins and the extent of the lesions in the MS/vDBB, we performed anti-ChAT and antiParv immunostainings to detect cholinergic and GABAergic neurons, respectively. In addition, staining for acetylcholinesterase (AChE) was performed in the hippocampus. AChE is the enzyme which degrades acetylcholine released in the synaptic cleft. In the hippocampus and a few other brain regions, its activity is considered to reflect the cholinergic innervation in a reliable way (e.g., Hoover et al., 1978; Satoh et al., 1983); the smallest the AChE activity in the target region of the septohippocampal cholinergic pathways, the greatest the cholinergic denervation. We performed AChE staining in both the dorsal and ventral subregions of the hippocampus because the MS and $\mathrm{vDBB}$ predominantly project to the former and the latter, respectively.

\section{Perfusion and Preparation of Tissue Sections}

At the completion of behavioral testing, rats were deeply anesthetized with an overdose of pentobarbital (100 mg/kg, ip). They were transcardially perfused with $60 \mathrm{ml}$ of phosphate-buffered $4 \%$ paraformaldehyde $\left(\mathrm{pH} 7.4 ; 4^{\circ} \mathrm{C}\right)$ over $5 \mathrm{~min}$. The brains were extracted, postfixed for $2 \mathrm{~h}$ in the same fixative $\left(4^{\circ} \mathrm{C}\right)$, and transferred into a $0.1 \mathrm{M}$ phosphate-buffered $20 \%$ sucrose solution in which they were left for about $48 \mathrm{~h}\left(4^{\circ} \mathrm{C}\right)$. Based on a series of preliminary comparisons, we established that these fixation/postfixation conditions allowed an acceptable immunostaining and a good preservation of AChE activity in the hippocampus. Indeed, based on our experience, a strong fixation (larger volume perfused or/and prolonged postfixation) improves contrast of anti-Parv immunostaining, but degrades AChE activity, as known since the early descriptions of the histochemical staining method for this enzyme (see comments by Butcher, 1984). Brains were subsequently frozen and kept at $-80^{\circ} \mathrm{C}$ until sectioning. Serial 30 - or $60-\mu \mathrm{m}$ thick sections were cut in the coronal plane at $-23^{\circ} \mathrm{C}$ using a freezing microtome. The sections were collected and kept floating in a cryoprotectant solution for immunostainings $(60-\mu \mathrm{m}$ thick) or mounted on gelatin-coated slides for AChE histochemistry (30- $\mu \mathrm{m}$ thick). 


\section{MS/vDBB anti-ChAT and anti-Parv Immunostainning and Hippocampal AChE Staining}

Protocols of both immunostainings have been detailed in the study of Traissard et al. (2007). As primary antibodies, we used a goat polyclonal antibody directed against ChAT (1:500; Chemicon International, Temecula, CA) and a mouse monoclonal antibody directed against Parv (1:4000; Sigma-Aldrich, P 3088, St. Louis, MO), whereas donkey anti-goat (ChAT) and horse anti-mouse (Parv) biotinylated secondary antibody (1:500, Vector Laboratories International, Burlingame, CA) were used. AChE histochemistry was performed according to Koelle (1954) with minor modifications: ethopropazine (0.3 mM; Sigma, St. Louis, MO) was used to block nonspecific cholinesterases and acetylcholine iodide $(4 \mathrm{mM}$; Sigma, St Louis, MO) was used as the substrate.

\section{Quantification of Lesion Extent and Selectivity Quantification of AChE-positive staining}

The extent of the cholinergic denervation of the dorsal and ventral subregions of the hippocampus was quantified by optical density (OD) measurements (dorsal and ventral separately from each other) as described in detail elsewhere (e.g., Traissard et al., 2007). Using a computer-assisted image analysis system (SAMBA Technologies, Meylan, France) coupled to a monochrome charge coupled device digital Sony (Japan) video camera (Model XC 77CE) equipped with a $60 \mathrm{~mm}$ Nikkon objective (Nikkor) and a Triplux extension tube; the mean OD was measured on digitalized images after precise delineation of each brain region of interest (dorsal hippocampus at $-3.8 \mathrm{~mm}$ from Bregma and ventral hippocampus at about $-5.3 \mathrm{~mm}$ from Bregma). For each rat, measures from each hemisphere were taken on two sections separated from each other by about 200 $\mu \mathrm{m}$ (these data were averaged with respect to the region). For digitalization, sections were placed on a Kaiser Prolite 5000 light box (Kaiser Fototechnik, Buchen, Germany). Magnification from section to computer screen was 28. The mean OD considered as a "background" and subtracted from all measures before analysis was obtained from a value taken for each rat and each section in the corpus callosum, where almost no AChE-positive reaction products could be identified. Moreover, to avoid differences due to the quality of the staining which could have varied from slide to slide (a slide comprising a maximum of 4 hippocampal slices out of 12 for each subregion of the hippocampus) all values were normalized by a ratio obtained from the measurement of the medial thalamus OD.

\section{ChAT-positive Cell Counting in the MS/vDBB}

To obtain an estimation of the lesion extent/selectivity induced by both neurotoxins, a section was chosen at the position $+1.2 \mathrm{~mm}$ from Bregma according to the atlas of Paxinos and Watson (1998). Anatomical landmarks were used to select, define, and standardize the location of the quantification frames of a set size in the MS and the vDBB. For cell counting, given the number of different immunostainings performed and the relatively tight antero-posterior extent of the intraseptal region in which the toxins were injected, we did not use an unbiased stereological method. In fact, counting was made on a particular section corresponding to an anteriority of Bregma +0.70 to $+0.90 \mathrm{~mm}$ for counting of MS and vDBB neurons. The number of ChAT-positive neurons was determined separately in the MS and vDBB (left and right). The MS was defined dorsally and laterally by the distribution of stained neurons, and ventrally by a virtual line joining the most dorsal level of the anterior commissures (Marques-Pereira et al., 2005). The same line was used to define the dorsal limit of the vDBB. The ventral limits of the $\mathrm{vDBB}$ corresponded to a virtual line joining the medial and most dorsal parts of each anterior commissure and the midline on the ventral edge of the section (see Supporting Information).

\section{Quantification of the ODs of Parv-Immunopositive Staining}

Due to the perfusion protocol used, although Parv-positive staining was optimal in brain regions such as the cortex and the striatum (see Supporting Information Fig. 1 for typical illustrations), there was, as expected, a weaker staining in the septal region, resulting in an obvious loss of contrast between the immunopositive neurons and the background or extrasomatic staining (see Fig. 4E,F). Therefore, we assessed ODs of Parv-immunostainings. Immunostained sections were analyzed using a light microscope (Leica DM550B) equipped with a motorized $\mathrm{X}-\mathrm{Y}$ sensitive stage and a video camera connected to a computerized image analysis system (Mercator, Explora Nova, La Rochelle, France). Using the mapping software Mercator, rectangular frames were drawn bilaterally over the regions under investigation, i.e., the MS and the vDBB $(+1.2 \mathrm{~mm}$ from Bregma according to the atlas of Paxinos and Watson, 1998) (Fig. 4). The same frames were used for each section and animal using the navigator. Relative ODs were measured bilaterally over the 2 regions of interest. Maximal transmission was measured within the genu of the corpus callosum. To avoid taking into account possible influence of nonspecific staining due to the secondary antibody, control slides were subjected to the Parv staining procedure except that they were not incubated with the primary antibody but with PBS-Triton instead (see Fig. 4). The OD values measured in negative control sections (i.e., nonspecific staining) were subtracted from the OD values of the analyzed sections.

\section{Populations of Rats in Each Retention Test for the Statistical Analysis}

Besides rats that could not be included due to lesions of insufficient extent, a few animals were removed due to the presence of abnormal behavior during the retention test, i.e., excessive floating (when the rats spent more than $50 \%$ of the time immobile once placed in the water) or excessive thigmotaxis (when the rat spent more than $50 \%$ of the time swimming 
along the edge of the pool not searching for the platform). Thus, final group sizes were (in parenthesis): 1-day: SHAM (9), SAP (10), OREX (9), and SAP/OREX (9); 5-day: SHAM (12), SAP (9), OREX (9), and SAP/OREX (9); and 25-day: SHAM (10), SAP (8), OREX (10), and SAP/OREX (11).

\section{Statistical Analyses}

Performances during the training phase of the water-maze experiment were analyzed by means of a three-way analysis of variance (ANOVA) with Group and Retention delay as between-subject factors and Training day as the within-subject factor. Probe trial performances were analyzed according to a double statistical logic: we first assessed between-group differences across the retention tests by means of a two-way ANOVA with Group and Retention delay as the between-subject factors, followed by separate analyses at each delay using one-way ANOVAs with Group as the factor; then, for each group, we compared performances (time in \% spent in the target quadrant) with chance level (i.e. 25\%) at each retention test using single one-sample $t$-test. Regarding histological measures, a first analysis considered three factors: Group, Retention delay, and Side. As there was neither significant Side effect $(P>0.1)$ nor a significant interaction between Side and the other factors $(P>0.1$ in each case), values from both sides were pooled and subsequent analyses at each retention delay were performed using one-way or two-way ANOVAs. Significant main effects or interactions were further analyzed using the Newman-Keuls post hoc test to assess differences between groups or, within a single group, between retention delays. $P$ values were considered significant when $<0.05$. In some cases, however, which are indicated in the Results section and were motivated by the general layout of the data or by a tendency, multiple comparisons were performed in the absence of a significant interaction, as advocated by Howell (1992) with reference to the NewmanKeuls test (Winer, 1971).

\section{RESULTS}

\section{None of the Lesion Types Prevented Acquisition} of the Platform Location

Analysis of the distance to reach the platform over the 6 days of training showed a significant overall effect of Group $\left(F_{(3,103)}\right.$ $=4.71, P<0.01)$ and Training day $\left(F_{(5,515)}=250.17, P<\right.$ $0.0001)$, but no effect of the Retention delay $\left(F_{(2,103)}=1.14\right.$, $P>0.1)$. Performances are shown in Figure 1A. There were significant Group $\times$ Training day $\left(F_{(15,515)}=1.89, P<0.05\right)$ and Training day $\times$ Retention delay $\left(F_{(10,515)}=1.87, P<\right.$ $0.05)$ interactions, but neither Group $\times$ Retention delay $\left(F_{(6,103)}=0.58, P>0.1\right)$ nor Group $\times$ Training day $\times$ Retention delay $\left(F_{(30,515)}=0.69, P>0.1\right)$ ones. Regarding the Group effect, multiple comparisons showed that the overall (collapsed over days) performance levels were significantly

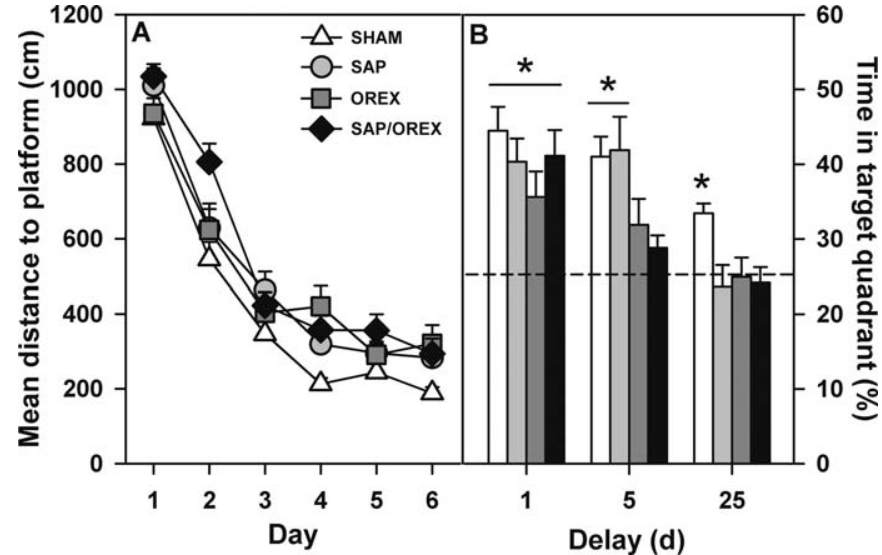

FIGURE 1. Behavioral performance in the water-maze test. A: During the training phase, the mean distance $( \pm S E M)$ to the platform improved over days in all groups and reached similar levels at the end of training. B: Performances [time in \% ( \pm SEM $)$ spent in the target quadrant] during the retention tests (probe trials). At 1-day all groups remembered the platform location. The OREX and SAP/OREX groups were impaired at 5-day and 25-day. SAP rats were impaired only at the 25 -day delay. SHAM rats, however, showed performances above chance at each delay $\left[{ }^{*} P<0.05\right.$ vs. chance level $(25 \%$ time spent in the target quadrant)].

impaired in OREX and SAP/OREX rats $(P<0.05)$ when compared with SHAM rats, and tended to be so in SAP rats $(P=$ $0.08)$; in average, the overall distances to reach the platform were by $0.5-1 \mathrm{~m}$ longer in SAP, OREX, and SAP/OREX rats than in their SHAM counterparts. Based on the Group $X$ Training day interaction, multiple comparisons revealed that over the 6 days of training, the only difference in the performances on a given day was seen on training day 2 between the SAP and SAP/OREX rats $(P<0.01)$, all other comparisons showing that the differences were not significant $(P>0.1$ in each case). This interaction thus remains difficult to understand with regard to Figure $1 \mathrm{~A}$, and if it can be statistically reduced to the difference found on day 2, even the latter remains difficult to interpret in a behavioral context. Moreover, the fact that on days 4 to 6 of the training phase there were no differences among groups further indicates that all groups had reached an equivalent level of performance at the end of the training phase, which was also confirmed at the shortest probe trial delay (1day) (see below and Fig. 1B).

\section{MS/vDBB Cholinergic and GABAergic Lesions Differentially Affected Recent and Remote Memories}

Performances during the retention tests are depicted in Figure 1B. Analysis of the time (in \%) spent in the target quadrant across the three retention delays showed significant effects of Group $\left(F_{(3,103)}=6.81, P<0.001\right)$ and Retention delay $\left(F_{(2,103)}=20.33, P<0.0001\right)$, but no interaction between the two factors $\left(F_{(6,103)}=1.097, P>0.1\right)$. As indicated in the Materials and Methods section, even though the Group $\times$ Retention delay interaction was not significant, we performed 
additional one-way ANOVAs with respect to each delay. These subsequent analyses showed that whereas there was no effect of Group on 1-day $\left(F_{(3,33)}=1.10, P>0.1\right)$, a significant effect of Group was found on both 5-day and 25-day $\left(F_{(3,35)}=\right.$ 4.41, $P<0.01$ and $F_{(3,35)}=4.66, P<0.01$, respectively). For each delay, between-group comparisons showed that (1) at 1-day, there was no difference among the four groups $(P>0.1$ for each comparison); (2) at 5-day performances of SHAM and SAP rats significantly differed from those of OREX and SAP/ OREX rats $(P<0.05$ for each comparisons), but the difference between OREX and SAP/OREX rats was not significant $(P>$ 0.1 for each comparison); (3) at 25-day performances of SHAM rats were significantly better than in the other three groups ( $P<0.05$ for each comparisons), whereas those of SAP, OREX, and SAP/OREX rats did not differ from each other $(P>0.1$ for each comparison). Analysis of retention performances compared to chance level $(25 \%$ of the time spent in the target quadrant) at the three delays by means of one-sample $t$ tests yielded the following results, and thus provided further statistical support to the aforementioned observations: (1) at 1day performances of all groups were significantly above chance level $(P<0.01$ for the SHAM, SAP, and SAP/OREX groups and $P<0.05$ for the OREX group); (2) at 5-day only performances of the SHAM and SAP rats were significantly above chance $(P<0.01$ for each group), those of the OREX and SAP/OREX rats being not different from it $(P>0.1$ for each group); (3) at 25-day only performances of the SHAM rats were significantly above chance $(P<0.001)$; for SAP, OREX, and SAP/OREX rats $(P>0.1)$. These results are illustrated by the swim tracks recorded during each retention test; typical examples are shown in Fig. 2. Altogether, the data might indicate that Parv-positive GABAergic septohippocampal neurons are engaged during the early stages of spatial memory consolidation, whereas cholinergic ones become engaged later on. The analysis of the time spent in the region comprising the position of the platform enlarged by a $10-\mathrm{cm}$ annulus supported comparable conclusions (see Supporting Information Table 1).

We also established that the differences in performances recorded during the learning phase or retention trial were not due to decreased motivation or visual and/or sensorimotor disabilities or biases (see Supporting Information Figure 2).

\section{HISTOLOGY}

\section{The Toxins Predominantly Affected their} Respective Target Neurons

\section{Analysis of the $O D$ of $A C h E$ reaction products in the dorsal and the ventral subregions of the hippocampus}

As shown in Figure 3 and Table 1, there was a marked reduction of $\mathrm{AChE}$ reaction products in the dorsal and ventral hippocampi of the SAP and SAP/OREX groups as compared with the SHAM and OREX groups. Dorsal hippocampus: a Group effect was found at each delay as follows: 1-day $\left(F_{(3.33)}\right.$ $=139.73, P<0.0001), 5$-day $\left(F_{(3.35)}=57.99, P<0.0001\right)$, 25 -day $\left(F_{(3.35)}=52.6, P<0.0001\right)$. Between-group comparisons showed that at each delay OD values in the SAP and SAP/OREX groups, which did not differ from each other $(P>$ 0.1 , were significantly lower than those in the SHAM (between $-83 \%$ and $-96 \%$ ) and OREX (between -89 and $-95 \%)$ groups $(P<0.001$ for each comparison). Moreover, OD values of the OREX group were significantly lower than the SHAM ones at each of the three delays $[P<0.05$ for each comparison; the decrease reached 15\% (1-day), 25\% (5-day), and 33\% (25-day)]. Ventral hippocampus: a Group effect was found at each delay as follows: 1-d $\left(F_{(3.33)}=51.24, P<\right.$ $0.0001)$, 5-day $\left(F_{(3.35)}=36.25, P<0.0001\right), 25$-day $\left(F_{(3.35)}\right.$ $=22, P<0.0001)$. Between-group comparisons showed that at each delay OD values in the SAP and SAP/OREX groups, which did not differ from each other $(P>0.1)$, were significantly lower than OD values in the SHAM (between $-84 \%$ and $-93 \%$ ) and OREX (between $-77 \%$ and $-93 \%$ ) groups $(P<0.001$ for each comparison); the difference between SHAM and OREX groups was not significant $(P>0.1)$. Lesions of the cholinergic MS/vDBB population in the SAP and SAP/OREX animals induced a dramatic reduction of AChE activity in the hippocampus as compared with the SHAM group; this activity was minimally affected in the OREX group, and only at the level of the dorsal hippocampus.

\section{Analyses of the number of ChAT-positive neurons in the $S M / v D B B$}

As shown in Figure 4 and Table 1, there was a marked reduction of the staining of ChAT-positive neurons in the SAP and SAP/OREX groups as compared with the SHAM and OREX groups. For each of the retention delays there was an effect of Group (1-day, $F_{(3.33)}=41.97, P<0.0001$; 5-day, $F_{(3.35)}=42.87, P<0.0001$; and 25-day, $F_{(3.35)}=74.84, P<$ $0.0001)$. Between-group comparisons showed that at the 1-day and 5-day delays the number of ChAT-positive neurons of the SAP and SAP/OREX groups, which did not differ from each other $(P>0.1)$, were significantly lower than those of the SHAM (between $-95 \%$ and $-97 \%$ ) and OREX (around $-95 \%)$ groups $(P<0.0001$ for each comparison). The same was true at the 25-day delay, the number of ChAT-positive neurons in the SAP and SAP/OREX groups being also signifcantly lower than in the SHAM (about -95\%) and OREX (between $-85 \%$ and $-95 \%)$ groups $(P<0.001$ for each comparison). At this delay, however, the number of ChAT-positive neurons counted in the OREX rats was significantly lower than in the SHAM rats $(-25 \% ; P<0.01)$. Overall, these results show that the 192 IgG-saporin induced a marked depletion of the cholinergic neuronal population of the MS/vDBB in both the SAP and SAP/OREX animals. The differences found between the SHAM and OREX groups at the 25-day delay indicate that orexin-saporin slightly affected the cholinergic neuronal population in the long term. However, this depletion 

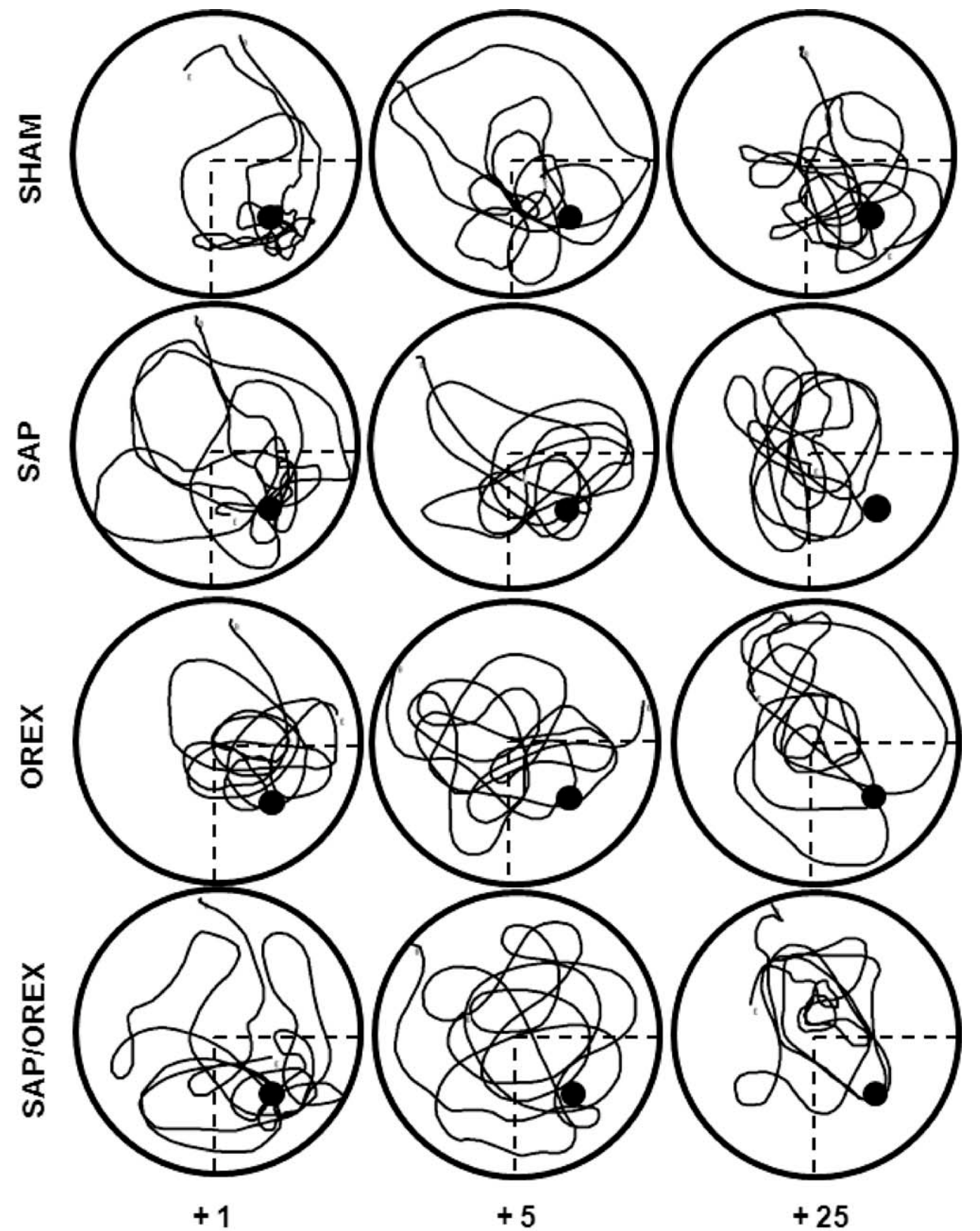

Delay (d)

FIGURE 2. Representative examples of swim paths recorded during the probe trial in the four groups of rats at each retention delay $(1,5$, or 25 days after the last acquisition trial). Each illustration shows the swim path of a rat which exhibited performance (\% of time spent in the target quadrant) that was the closest to the corresponding group mean. Notice that in OREX and SAP/ OREX rats the search pattern was not focused on the target quad- rant at 5-day and 25-day the postacquisition delays, whereas in the SAP rats, the focused search, which was still observed at the 5day delay, was clearly lost at the 25-day one. SHAM rats focused on the target quadrant at each delay, although with less insistence on 25-day as compared to 1-day or 5-day, but percent time in the target quadrant was above chance at all delays (see Fig. 1B). remained minimal. Moreover, the fact that at the 5-day delay the OREX group showed retention impairments, whereas the SAP group did not, indicated that such impairments could not be attributed to the slight depletion of the cholinergic septohippocampal pathway seen in the OREX group.

\section{Analysis of the $O D$ values of $S M / v D B B$ Parv-positive immunostaining}

As shown in Figure 4 and Table 1, there was a marked reduction of the level of Parv immunostainings in the OREX 
A

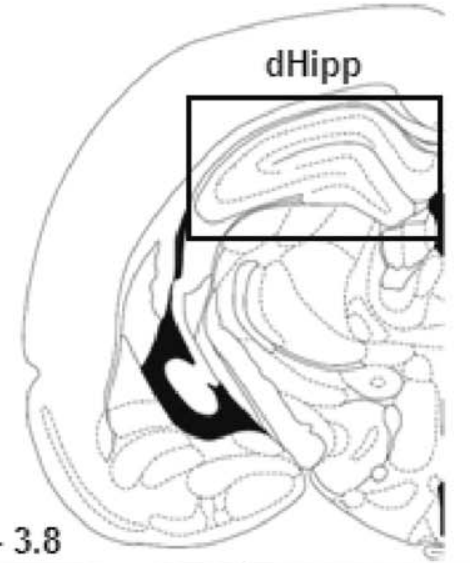

Bregma - 3.8
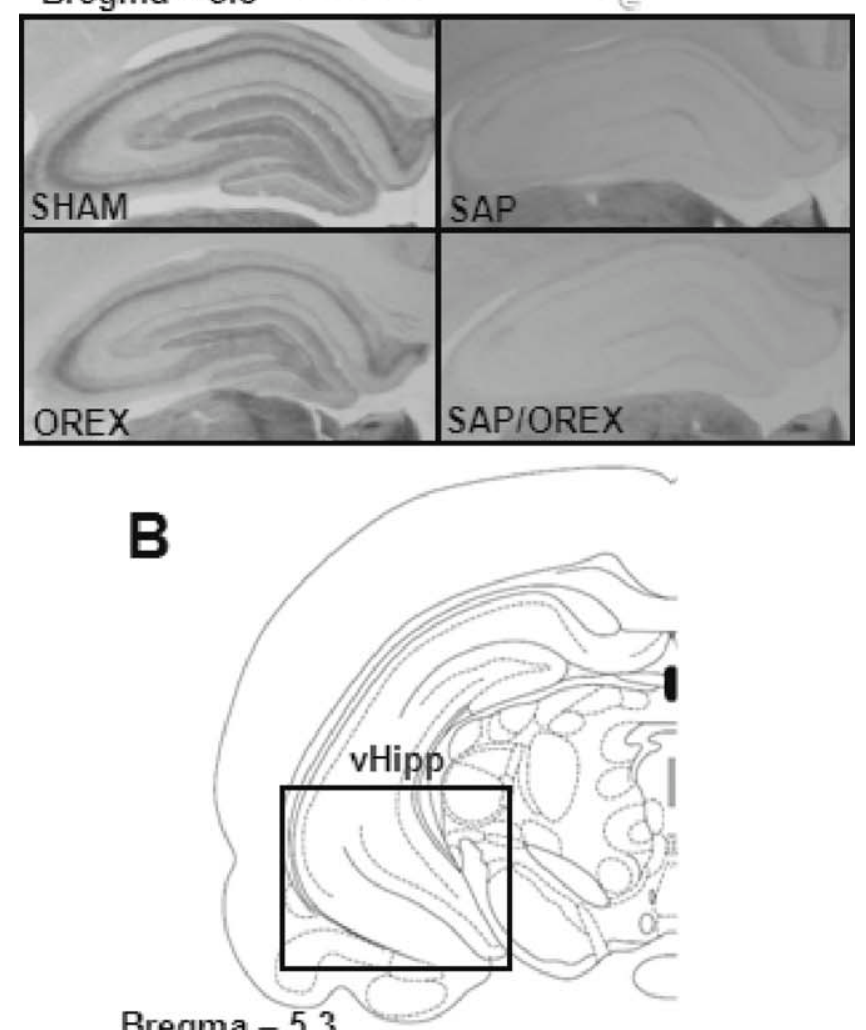

Bregma-5.3

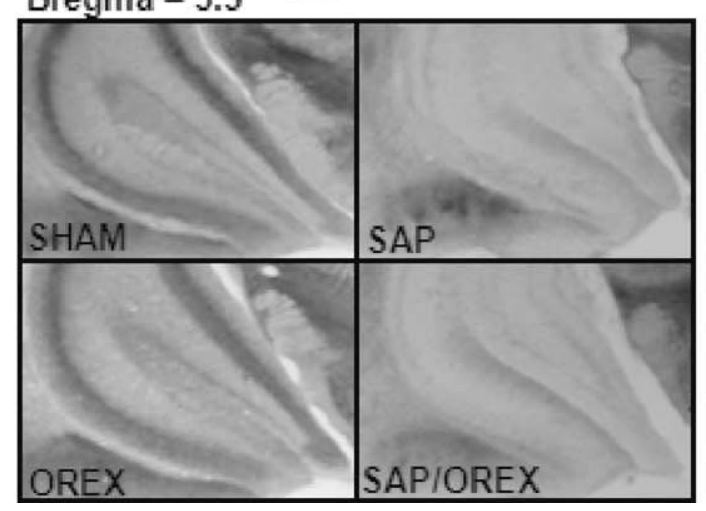

FIGURE 3. Representative microphotographs of AChE-positive staining on coronal sections through dorsal $(A)$ and ventral $(B)$ regions of the hippocampus. Although AChE activity was preserved in SHAM and OREX animals, it was almost totally abolished in SAP and SAP/ OREX animals, indicating a dramatic cholinergic denervation of the hippocampus (plates modified from Paxinos and Watson, 1998).

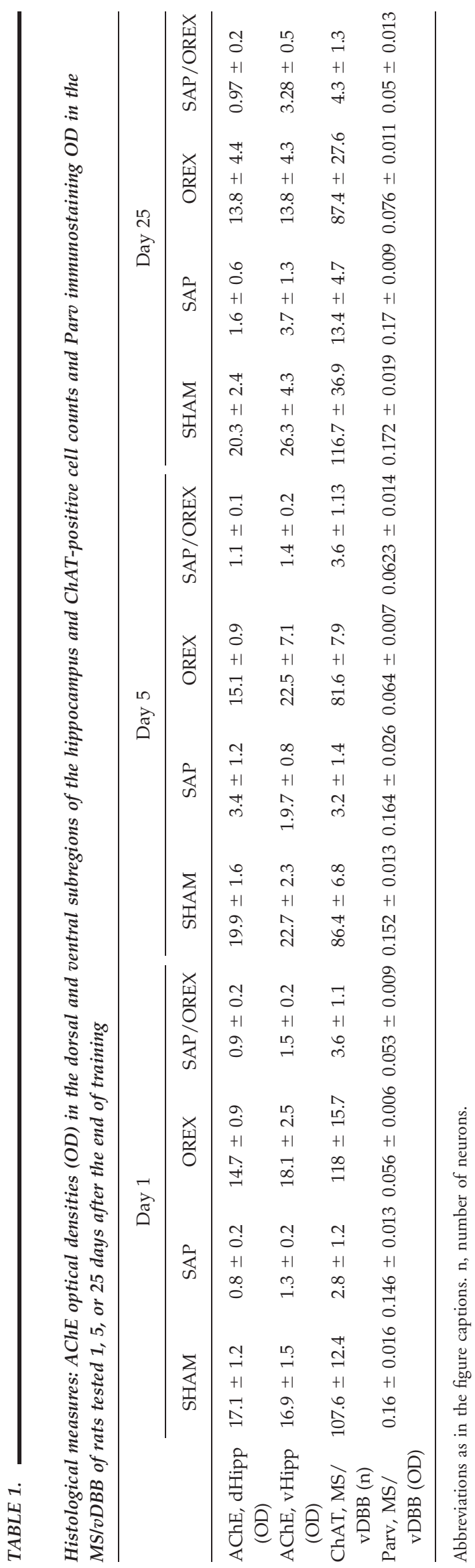




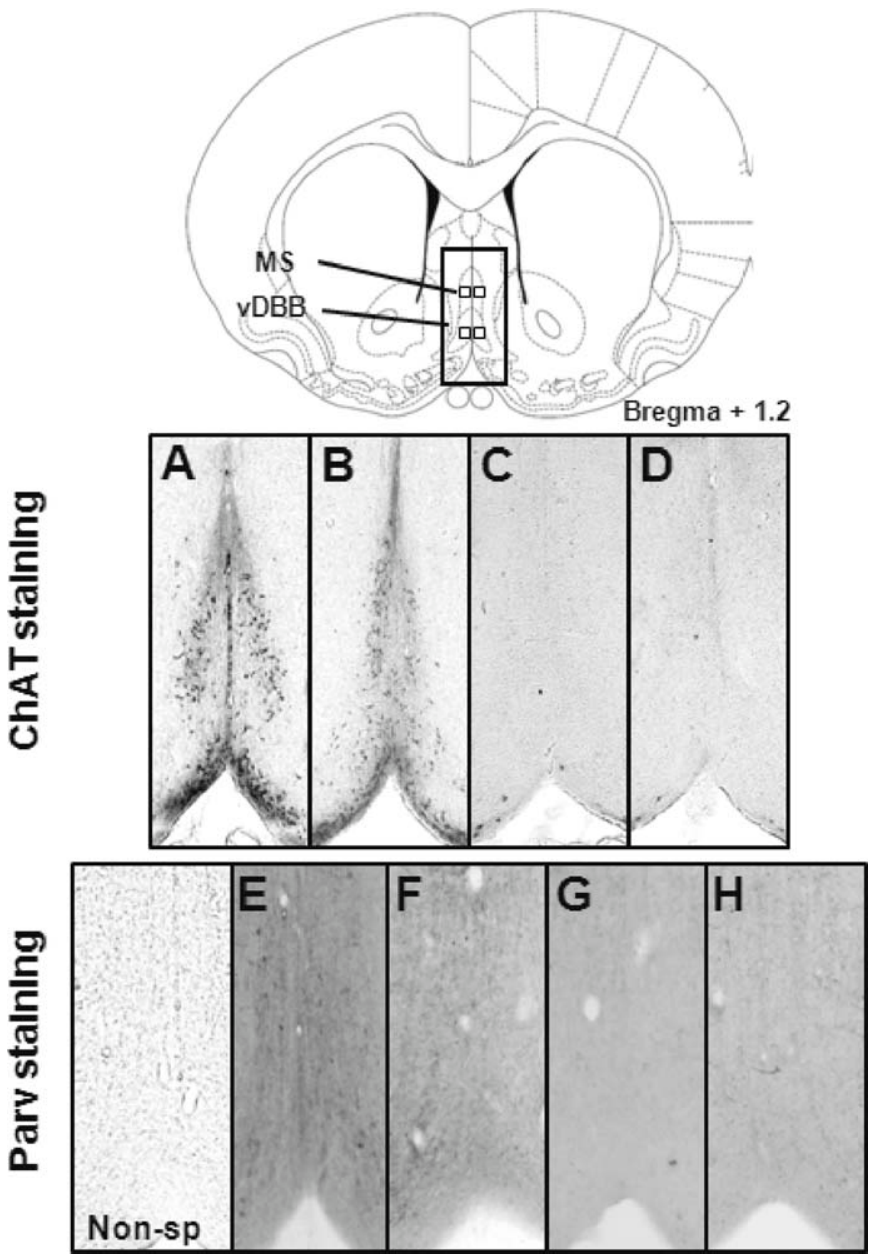

FIGURE 4. Representative images of ChAT (top) and Parv (bottom) immunostainings in SHAM (A and E), SAP (B and F), OREX (C and G), and SAP/OREX (D and G) rats. For anti-Parv immunostaining, a slice showing nonspecific staining (no primary antibody used during incubation) is also shown. In the MS/vDBB regions (plate modified from Paxinos and Watson, 1998), the two squares on each side delimit the regions where ODs for anti-Parv immunostaning were measured. Cholinergic neurons were markedly depleted in SAP (C) and SAP/OREX (D) and relatively spared in OREX (B) rats. GABA neurons were markedly depleted in OREX (G) and SAP/OREX $(\mathrm{H})$ and relatively preserved in SAP (F) rats. Both neuronal populations were unaltered in SHAM animals (A and $\mathrm{E}$ ).

and SAP/OREX groups when compared with the SHAM and SAP groups (between $-55 \%$ and $-70 \%$ ). A Group effect was found at each delay as follows: 1 -day $\left(F_{(3.33)}=22.70, P<\right.$ $0.0001)$, 5-day $\left(F_{(3.35)}=11.68, P<0.0001\right), 25$-day $\left(F_{(3.35)}\right.$ $=20.85, P<0.0001)$. Between-group comparisons showed that at each delay OD values in the SHAM and SAP groups, which did not differ from each other $(P>0.1)$, were significantly higher than those in the OREX (reduction of $-58 \%$ to $-65 \%$ ) and SAP/OREX (reduction of $-56 \%$ to $-70 \%$ ) groups $(P<0.01$ for each comparison).

In conclusion, the histological analyses revealed that both toxins predominantly lesioned their respective target neurons. One can also notice that they both induced damage to the other neuronal population, although in a limited and relatively small extent, which seemed to increase according to the time elapsed since surgery. The orexin-saporin neurotoxin binds to the hypocretin-2 receptor, which is also present on cholinergic neurons. Therefore, one cannot rule out a possible alteration of a small part of the latter neurons. On the other hand, the loss of GABAergic cells in rats treated with the 192 IgG-saporin could be the consequence of a postapoptotic intraparenchymal release of free radicals, which could in turn affect part of the surrounding neuronal populations in a nonspecific manner. This hypothesis, which also stands for the partial loss of cholinergic neurons in the OREX group, most probably requires a dedicated experiment.

\section{DISCUSSION}

Using immunotoxins in rats, this study assessed the contribution of septohippocampal GABAergic and cholinergic neurons to the persistence of a spatial memory tested at short (1day), intermediate (5-day), and long (25-day) postacquisition delays. Cholinergic and/or GABAergic lesions slightly affected overall performance levels during task acquisition, mainly in the first few days of the training period. Performance achieved at the end of training in the three lesion groups, however, did not differ from that found in controls. Furthermore, all groups displayed a swimming pattern accounting for retrieval of the platform location during the 1-day probe trial: they all performed above chance level. Rats with cholinergic lesions still remembered the task 5 days after acquisition, but were impaired at the 25-day delay. Rats with GABAergic lesions, alone or combined with cholinergic ones, were significantly impaired as early as 5 days postacquisition. These data point for the first time to the possibility of a sequential contribution of GABAergic and cholinergic septohippocampal neurons to spatial memory stabilization in the long term: as performance degradation was faster after GABAergic than after cholinergic lesions, it seems that GABAergic processes are engaged at an earlier stage than cholinergic ones during system consolidation of a spatial memory.

Neuropsychological investigations of memory functions in patient H.M. opened a new era in memory research, which led to evidence of a crucial role of the hippocampus in memory formation/reorganization but neither in processes supporting immediate memory nor in the repository of remote memories (Squire, 2009). Other clinical cases clearly pointed to a functional implication of the hippocampus in processing declarative memories and their consolidation (Victor and Agamanolis, 1990; Rempel-Clower et al., 1996). Whether this structure is also needed for recollecting remote memory traces, as postulated by the multiple trace theory of memory consolidation (Nadel and Moscovitch, 1997), or is not, as postulated by the standard theory of memory consolidation (Squire and Alvarez, 1995), is still a subject of debate. Nonetheless, whatever the theory, a functional hippocampus is a prerequisite for a 
memory consolidation process to be initiated. At the system level, however, the precise networks involved in - and the neuropharmacological processes governing-memory consolidation remain to be discovered; they are potential targets for treating memory dysfunctions. Beside the glutamatergic afferents originating in the entorhinal cortex, the cholinergic and GABAergic projections from the $S M / v D B B$ provide main regulatory inputs to the hippocampus. These projections modulate physiological processes classically associated with learning and memory consolidation, including long-term potentiation (Frey et al., 2003), theta rhythm (Bland et al., 1999), neurogenesis (Van der Broght et al., 2005), and expression of immediate-early genes such as Arc (Miyashita et al., 2009). In rodents, some of the memory deficits induced by reversible inactivation (e.g., Koenig et al., 2008) or complete lesions of the SM/vDBB (see Parent and Baxter, 2004, for a review) parallel those produced by hippocampal damage: animals with such damage do usually not acquire a water-maze task.

In this study, cholinergic and GABAergic lesions, either single or combined, did not prevent learning of a platform location. This absence of learning impairments after single lesions is in line with previous studies showing no acquisition deficits in the water maze following either cholinergic (intraseptal injections of 192 IgG-saporin: Berger-Sweeney et al., 1994; Baxter et al., 1995; Smith and Pang, 2005) or GABAergic lesions restricted to the septal region (intraseptal injections of kainite or orexin-saporin: Pang et al., 2001; Smith and Pang, 2005). However, with 192 IgG-saporin, depending on the strain or sex of rats used, the lesion extent, and the type of memory studied, some authors could evidence deficits which could be accounted for by additional damage outside the septohippocampal system (see Parent and Baxter, 2004, for a critical review). In the case of combined lesions, the lack of performance deficits among groups at the end of training might indicate that the acquisition deficits previously attributed to SM/ vDBB lesions-either electrolytic or by means of nonselective toxins - cannot be solely accounted for by cholinergic or/and GABAergic damage, a result compatible with the report by Pang et al. (2001). Moreover, in the current experiment, the memory generated during training lasted for at least 1 day in all groups, which is consistent with the literature: inactivation of the SM/vDBB shortly after training does not affect memory formation and retrieval at short postacquisition delays (1-24 h) (Rashidy-Pour et al., 1996; Koenig et al., 2008), suggesting that this structure is not crucial in the early phase of the consolidation process. Altogether, our results of the training phase and the 1-day retention test confirm that the GABAergic and cholinergic components of the septohippocampal interface are not crucial for learning and early consolidation of spatial knowledge, although they may contribute in terms of learning speed, as suggested by our observations: performances during the first training days were slightly but significantly affected by all lesions, but final performances levels were not significantly different among groups.

The novel and important results of this study are those of the retention tests at 5-day and 25-day. Here we report that septal cholinergic lesions induced deficits of only remote memory (25-day) whereas septal GABAergic lesions, as well as combined lesions, resulted in retrieval deficits at a largely shorter postacquisition delay (5-day).

The lack of impairments at 5-day in rats with lesions encroaching mainly onto cholinergic neurons shows that the cholinergic hippocampal innervation is not an essential factor of recent memory processing and confirms earlier studies (Berger-Sweeney et al., 1994; Baxter et al., 1995; Dornan et al., 1996). In the case of lesions encroaching onto GABAergic neurons, learning deficits have been reported. Dwyer et al. (2007) found that kainate-induced septal GABAergic lesions impaired sequential learning of different spatial locations in an eight-arm radial maze. Cahill and Baxter (2001) found that rats with a loss of septal GABAergic neurons were impaired in both place and response learning in a plus maze. From a pharmacological point of view, our results suggest that GABAergic neurons likely contribute to consolidation processes within the hippocampus (Zola-Morgan et al., 1986). As these neurons only project onto hippocampal GABAergic interneurons (Freund and Antal, 1988), the memory consolidation deficits resulting from septal GABAergic lesions could be the consequence of an increased GABAergic tonus-and thus an overall activity decrease-within the hippocampus. This hypothesis is in line with a large set of data. Substances with amnesic properties such as alcohol (White, 2003) or some anesthetics (Jevtovic-Todorovic et al., 2003) bind to-and positively modulate- $-\mathrm{GABA}_{\mathrm{A}}$ receptors (Franks and Lieb, 1994). Intrahippocampal administrations of agonists of both $\mathrm{GABA}_{\mathrm{A}}$ and $\mathrm{GABA}_{\mathrm{B}}$ receptors impair spatial learning and memory consolidation (Arolfo et al., 1998; Zarrindast et al., 2002). Finally, $G_{A B A}$ and $G A B A_{B}$ antagonists facilitate hippocampal synaptic plasticity (Aizawa et al., 1997; Matsuyama et al., 2008) and improve learning and memory consolidation (Luft et al., 2004; Helm et al., 2005).

At 25-day, all types of lesions induced memory impairments, showing that the involvement of the cholinergic septohippocampal pathway in the consolidation process takes place preferentially in the longer term. However, these results do not rule out the possibility that GABAergic and cholinergic septal neurons act synergistically to consolidate memory in the long term. In this study, we performed investigations of the lesions before the acquisition period, so that the damages were present during the whole course of testing. Therefore, it cannot be ruled out that the lesions have in fact interfered with the processes (or strength) of memory trace establishment, which might in turn have had consequences on the duration of the memory. It is noteworthy, however, that performance had reached comparable levels by the end of the training phase in all groups, whatever the lesion type, indicating that none of the lesions had disrupted the functional dynamic of memory formation processes. This remark is further supported by the fact that retention performances were comparable and even almost identical between groups at the 1-day delay. According to such an experimental design, however, it is not possible to conclude on the role of GABAergic neurons at the 25-day delay. Indeed, if 
the OREX rats could not remember the platform location as soon as 5 days after training, it is logical that they could not do so at a later time point. To clearly establish the role of GABAergic neurons in the long term it would be interesting to perform the lesions once the storage of recently acquired informations has been completed, i.e., at least 5 days following training. This particular point, however, remains to be addressed in a separate study. The impairments seen in rats with the single cholinergic lesion are likely to be due to the long-term effects of a prolonged deficit in acetylcholine release within the hippocampus. Indeed, a rise in hippocampal acetylcholine release correlates with spatial learning and memory (Fadda et al., 2000; McIntyre et al., 2003), whereas acetylcholine regulates hippocampal physiological mechanisms subserving memory consolidation, including synaptic plasticity (Huerta and Lisman, 1993; Leung et al., 2003) and neurogenesis (Mohapel et al., 2005). However, it is not known yet why and how cholinergic neurons impact on remote more than on recent memory consolidation. At the anatomical level, septal cholinergic neurons project onto both hippocampal GABAergic interneurons and pyramidal neurons (Frotscher and Leranth, 1985). This further suggests complex time-dependent excitatory and inhibitory processes related to distinct phases of memory consolidation. Vale-Martinez et al. (2002) showed that rats with selective cholinergic lesions of the MS/vDBB had no anterograde memory deficits for food preference, another hippocampus-dependent form of memory, for as long as 3 weeks. Therefore, it can also be concluded that the involvement of $\mathrm{MS} / \mathrm{vDBB}$ cholinergic neurons in remote memory processing depends on the type of memory used, and could be relatively specific to spatial memory, a function which in the long-term might remain hippocampus-dependent (Moscovitch, 2006).

This study is the first one to show that distinct pharmacological processes within the septohippocampal interface contribute conjointly to memory consolidation at a system level and could do so in a sequential way. Indeed, memory degradation was faster after GABAergic than after cholinergic damage in the septal region. Our data bring further light on the debate about the involvement of the cholinergic septohippocampal pathways in spatial memory processing and suggest that these pathways could be required for memory consolidation in the long term, most probably after an earlier contribution of septohippocampal GABAergic mechanisms. Thus, our current results might provide additional paves on the way towards a better understanding of anterograde amnesia associated with neurological or psychiatric diseases, perhaps particularly with regard to the implications of cholinergic and/or GABAergic dysfunctions in pathological aging and perhaps also in schizophrenia. Although still highly speculative, it is tempting to propose the following reflection: while newly formed memories are dependent on the hippocampus for a limited time, their storage/retrieval once mature and remote seems to depend on processes engaging cortical structures, either in an apparently exclusive way for some forms of memories, such as for fear, or in cooperation with the hippocampus for others, such as for spatial information. Thus, a cooperation between cortical and hippocampal structures arises progressively when the memory ages, and this process is triggered by "online" or "offline" reactivations of hippocampal-cortical networks (e.g., Frankland and Bontempi, 2005). It seems reasonable to consider that such reactivations achieve optimal efficiency if both of these structures are normally functional. If the cholinergic and GABAergic fibers of the septohippocampal pathways exert excitatory influences in the hippocampus, be they direct (cholinergic) or indirect (GABAergic), it can be conceived that the combination of both lesions could result in a significant and lasting decrease of hippocampal activity, thereby reducing the efficiency of the hippocampus in its contribution to the hippocampal-cortical dialog supposed to end up in the reorganization of the memory for its long-term storage. It is thus possible that the postacquisition trace duration has been proportional to the magnitude of the hippocampal activity reduction and that the GABAergic lesion had the largest contribution to this reduction.

\section{Acknowledgments}

The authors are grateful to O. Bildstein, D. Egesi, and G. Edomwonyi for their assistance in animal care. This research was supported by the French Agence Nationale de la Recherche (ANR-06-NEURO-027-04), the CNRS, INSERM and the UdS.

\section{REFERENCES}

Aizawa M, Ito Y, Fukuda H. 1997. Roles of gamma-aminobutyric acidB (GABA B) and gamma-hydroxybutyric acid receptors in hippocampal long-term potentiation and pathogenesis of absence seizures. Biol Pharm Bull 20:1066-1070.

Arolfo MP, Zanudio MA, Ramirez OA. 1998. Baclofen infused in rat hippocampal formation impairs spatial learning. Hippocampus 8:109-113.

Baxter MG, Bucci DJ, Gorman LK, Wiley RG, Gallagher M. 1995. Selective immunotoxic lesions of basal forebrain cholinergic cells: Effects on learning and memory in rats. Behav Neurosci 109:714-722.

Berger-Sweeney J, Heckers S, Mesulam MM, Wiley RG, Lappi DA, Sharma M. 1994. Differential effects on spatial navigation of immunotoxin-induced cholinergic lesions of the medial septal area and nucleus basalis magnocellularis. J Neurosci 14:4507-4519.

Bland BH, Oddie SD, Colom LV. 1999. Mechanisms of neural synchrony in the septohippocampal pathways underlying hippocampal theta generation. J Neurosci 19:3223-3237.

Book AA, Wiley RG, Schweitzer JB. 1992. Specificity of 192 IgG-saporin for NGF-receptor positive cholinergic basal forebrain neurons in the rat. Brain Res 590:350-355.

Butcher L. 1984. Acetylcholinesterase histochemistry. In: Björklund A, Hökfelt T, editors. Handbook of Chemical Neuroanatomy: Methods in Chemical Neuroanatomy. Amsterdam: Elsevier. pp 1-49.

Cahill JF, Baxter MG. 2001. Cholinergic and noncholinergic septal neurons modulate strategy selection in spatial learning. Eur J Neurosci 14:1856-1864.

Dornan WA, McCampbell AR, Tinkler GP, Hickman LJ, Bannon AW, Decker MW, Gunther KL. 1996. Comparison of site-specific injections into the basal forebrain on water maze and radial arm maze performance in the male rat after immunolesioning with 192 IgG saporin. Behav Brain Res 82:93-101. 
Dwyer TA, Servatius RJ, Pang KC. 2007. Noncholinergic lesions of the medial septum impair sequential learning of different spatial locations. J Neurosci 27:299-303.

Fadda F, Cocco S, Stancampiano R. 2000. Hippocampal acetylcholine release correlates with spatial learning performance in freely moving rats. Neuroreport 11:2265-2269.

Frankland PW, Bontempi B. 2005. The organization of recent and remote memories. Nat Rev Neurosci 6:119-130.

Franks NP, Lieb WR. 1994. Molecular and cellular mechanism of general anesthesia. Nature 367:607-614.

Freund TF, Antal M. 1988. GABA-containing neurons in the septum control inhibitory interneurons in the hippocampus. Nature 336:170-173.

Frey S, Bergado JA, Frey JU. 2003. Modulation of late phases of long-term potentiation in rat dentate gyrus by stimulation of the medial septum. Neuroscience 118:1055-1062.

Frotscher M, Leranth C. 1985. Cholinergic innervation of the rat hippocampus as revealed by choline acetyltransferase immunocytochemistry: A combined light and electron microscopic study. J Comp Neurol 239:237-246.

Hangya B, Borhegyi Z, Szilágyi N, Freund TF, Varga V. 2009. GABAergic neurons of the medial septum lead the hippocampal network during theta activity. J Neurosci 29:8094-8102.

Helm KA, Haberman RP, Dean SL, Hoyt EC, Melcher T, Lund PK, Gallagher M. 2005. GABA $\mathrm{B}_{\mathrm{B}}$ receptor antagonist SGS742 improves spatial memory and reduces protein binding to the cAMP response element (CRE) in the hippocampus. Neuropharmacology 48:956-964.

Hoover DB, Muth EA, Jacobowitz DM. 1978. A mapping of the distribution of acetycholine, choline acetyltransferase and acetylcholinesterase in discrete areas of rat brain. Brain Res 153:295-306.

Howell D. 1992. Statistical Methods for Psychology. Belmont: Duxburry Press. $338 \mathrm{p}$.

Huerta PT, Lisman JE. 1993. Heightened synaptic plasticity of hippocampal CA1 neurons during a cholinergically induced rhythmic state. Nature 364:723-725.

Jevtovic-Todorovic V, Hartman RE, Izumi Y, Benshoff ND, Dikranian K, Zorumski CF, Olney JW, Wozniak DF. 2003. Early exposure to common anesthetic agents causes widespread neurodegeneration in the developing rat brain and persistent learning deficits. J Neurosci 23:876-882.

Kelsey JE, Landry BA. 1988. Medial septal lesions disrupt spatial mapping ability in rats. Behav Neurosci 102:289-293.

Koelle GB. 1954. The histochemical localization of cholinesterases in the central nervous system of the rat. J Comp Neurol 100:211-235.

Koenig J, Cosquer B, Cassel JC. 2008 Activation of septal 5-HT1A receptors alters spatial memory encoding, interferes with consolidation, but does not affect retrieval in rats subjected to a water-maze task. Hippocampus 18:99-118.

Lehmann O, Grottick AJ, Cassel JC, Higgins GA. 2003. A double dissociation between serial reaction time and radial maze performance in rats subjected to $192 \mathrm{IgG}$-saporin lesions of the nucleus basalis and/or the septal region. Eur J Neurosci 18:651-666.

Leung LS, Shen B, Rajakumar N, Ma J. 2003. Cholinergic activity enhances hippocampal long-term potentiation in CA1 during walking in rats. J Neurosci 23:9297-9304.

Lopez J, Pereira de Vasconcelos A, Cassel JC. 2008a. Environmental cue saliency influences the vividness of a remote spatial memory in rats. Neurobiol Learn Mem 90:285-289.

Lopez J, Pereira de Vasconcelos A, Cassel JC. 2008b. Differential sensitivity of recent vs. remote memory traces to extinction in a watermaze task in rats. Neurobiol Learn Mem 90:460-466.

Luft T, Pereira GS, Cammarota M, Izquierdo I. 2004. Different time course for the memory facilitating effect of bicuculline in hippocampus, entorhinal cortex, and posterior parietal cortex of rats. Neurobiol Learn Mem 82:52-56.

Lüttgen M, Ogren SO, Meister B.(2005. 5- $\mathrm{HT}_{1 \mathrm{~A}}$ receptor mRNA and immunoreactivity in the rat medial septum/diagonal band of
Broca-relationships to GABAergic and cholinergic neurons. J Chem Neuroanat 29:93-111.

Marques-Pereira P, Cosquer B, Schimchowitsch S, Cassel JC. 2005. Hebb-Williams performance and scopolamine challenge in rats with partial immunotoxic hippocampal cholinergic deafferentation. Brain Res Bull 64:381-394.

Matsuyama S, Taniguchi T, Kadoyama K, Matsumoto A. 2008. Longterm potentiation-like facilitation through GABAA receptor blockade in the mouse dentate gyrus in vivo. Neuroreport 19:18091813.

McIntyre CK, Marriott LK, Gold PE. 2003. Patterns of brain acetylcholine release predict individual differences in preferred learning strategies in rats. Neurobiol Learn Mem 79:177-183.

Miyashita T, Kubik S, Haghighi N, Steward O, Guzowski JF. 2009. Rapid activation of plasticity-associated gene transcription in hippocampal neurons provides a mechanism for encoding of one-trial experience. J Neurosci 29:898-906.

Mohapel P, Leanza G, Kokaia M, Lindvall O. 2005. Forebrain acetylcholine regulates adult hippocampal neurogenesis and learning. Neurobiol Aging 26:939-946.

Nadel L, Moscovitch M. 1997. Memory consolidation, retrograde amnesia and the hippocampal complex. Curr Opin Neurobiol 7:217227.

Pang KC, Nocera R, Secor AJ, Yoder RM. 2001. GABAergic septohippocampal neurons are not necessary for spatial memory. Hippocampus 11:814-827.

Parent MB, Baxter MG. 2004. Septohippocampal acetylcholine: Involved in but not necessary for learning and memory? Learn Mem 11:9-20.

Paxinos G, Watson C. 1995. The Rat Nervous System, 2nd ed. San Diego, CA: Academic Press. 1136 p.

Paxinos G, Watson C. 1998. The Rat Brain in Stereotaxic Coordinates, 4th ed. San Diego, CA: Academic Press.

Rashidy-Pour A, Motamedi F, Motahed-Larijani Z. 1996. Effects of reversible inactivations of the medial septal area on reference and working memory versions of the Morris water maze. Brain Res 709:131-140.

Rempel-Clower NL, Zola SM, Squire LR, Amaral DG. 1996. Three cases of enduring memory impairment after bilateral damage limited to the hippocampal formation. J Neurosci 16:52335255.

Satoh K, Armstrong DM, Fibiger HC. 1983. A comparison of the distribution of central cholinergic neurons as demonstrated by acetylcholinesterase pharmacohistochemistry and choline acetyltransferase immunohistochemistry. Brain Res Bull 11:693-720.

Smith HR, Pang KC. 2005. Orexin-saporin lesions of the medial septum impair spatial memory. Neuroscience 132:261-271.

Squire LR. 2009. The legacy of patient H.M. for neuroscience. Neuron 61:6-9.

Squire LR, Alvarez P. 1995. Retrograde amnesia and memory consolidation: A neurobiological perspective. Curr Opin Neurobiol 5:169-177.

Traissard N, Herbeaux K, Cosquer B, Jeltsch H, Ferry B, Galani R, Pernon A, Majchrzak M, Cassel JC. 2007. Combined damage to entorhinal cortex and cholinergic basal forebrain neurons, two early neurodegenerative features accompanying Alzheimer's disease: Effects on locomotor activity and memory functions in rats. Neuropsychopharmacology 32:851-871.

Vale-Martínez A, Baxter MG, Eichenbaum H. 2002. Selective lesions of basal forebrain cholinergic neurons produce anterograde and retrograde deficits in a social transmission of food preference task in rats. Eur J Neurosci 16:983-998.

Van der Borght K, Mulder J, Keijser JN, Eggen BJ, Luiten PG, Van der Zee EA. 2005. Input from the medial septum regulates adult hippocampal neurogenesis. Brain Res Bull 67:117-125.

Van der Staay FJ, Bouger P, Lehmann O, Lazarus C, Cosquer B, Koenig J, Stump V, Cassel JC. 2006. Long-term effects of immuno- 
toxic cholinergic lesions in the septum on acquisition of the conefield task and noncognitive measures in rats. Hippocampus 16: 1061-1079.

Victor M, Amaganolis D. 1990. Amnesia due to lesions confined to the hippocampus: A clinical-pathologic study. J Cognit Neurosci 2:246-257.

Waite JJ, Wardlow ML, Chen AC, Lappi DA, Wiley RG, Thal LJ. 1994. Time course of cholinergic and monoaminergic changes in rat brain after immunolesioning with 192 IgG-saporin. Neurosci Lett 169:154-158.

White AM. 2003. What happened? Alcohol, memory blackouts and the brain. Alcohol Res Health 27:186-196.
Winer BJ. 1971. Statistical Principles in Experimental Design. New York: McGraw-Hill Book Company, 907 p.

Yoder RM, Pang KC. 2005. Involvement of GABAergic and cholinergic medial septal neurons in hippocampal theta rhythm. Hippocampus 15:381-392.

Zarrindast MR, Bakhsha A, Rostami P, Shafaghi B. 2002. Effects of intrahippocampal injection of GABAergic drugs on memory retention of passive avoidance learning in rats. J Psychopharmacol 16:313-319.

Zola-Morgan S, Squire LR, Amaral DG. 1986. Human amnesia and the medial temporal region: Enduring memory impairment following a bilateral lesion limited to field CA1 of the hippocampus. J Neurosci 6:2950-2967. 